\title{
Formation of the psychological mobilisation state to achieve one's best sporting result
}

\author{
Gennady Andreevich Gilev ${ }^{2 *}$, Vasilisa Vladimirovna Vladykina ${ }^{1}$, Marina Alexandrovna \\ Semenova $^{2}$, Yuriy Igorevich Chernov $^{2}$, and Vadim Nikolaevich Gladkov ${ }^{3}$ \\ ${ }^{1}$ Federal State Budgetary Educational Institution of Higher Education "Moscow Pedagogical State \\ University" (MPSU), Moscow, Russia \\ ${ }^{2}$ Federal State Budgetary Educational Institution of Higher Education "Moscow Polytechnic \\ University (MPU), Moscow, Russia \\ ${ }^{3}$ Center for Sports Innovative Technologies and Training of National Teams of the Moscow \\ Department of Sports and Tourism, Moscow, Russia
}

\begin{abstract}
During the training process before the competition, the athlete often shows a high result similar to, and sometimes exceeding, his previously achieved record. However, in the conditions of the following competitive activity, especially in tough sports competition, there is a decrease in effectiveness. This circumstance is often explained by a poor shape of a sportsman. While a more correct objective indicator of the decrease in effectiveness during the competition, as many experts claim, is the psycho-pedagogical mobilisation unpreparedness of an athlete. The aim of this research was to mobilise the strong-willed qualities of highly qualified swimmers, which allow a sportsman to demonstrate his or her best or equal to previously achieved sporting results during important competitions, involving psychological and pedagogical methods. During the implementation of this goal, methods helping to form person's strongwilled qualities were used, including psychological and pedagogical methods. The results were obtained. They positively characterize applied psychological and pedagogical methods, which effectiveness was proved by the higher level of record achievements shown by the overwhelming majority of participants in the pedagogical experiment during the competitive activities implementation, as well as in the moral and volitional state rise when overcoming the competitive distance. It has been shown that the use of psychological and pedagogical activities together with autotraining contributes to the formation of an internal mood, the state of assemblage and eagerness to achieve one's best result.
\end{abstract}

\section{Introduction}

The athletes' training process is planned and implemented in such a way that physical, functional, technical and other aspects of preparation for a performance in important competitions are at the highest possible level. With successful preparation, the athlete on the main start eve often demonstrates his best results. However, there are numerous cases

* Corresponding author: ga.gilev@mpgu.edu 
when during the main start an athlete has a decrease in effectiveness. He or she fails to improve or repeat the result achieved on the competition's eve. Often, there are cases of a significant decrease in the effectiveness of highly qualified athletes. The relevance of this issue is justified by numerous examples of an effectiveness' decrease in serious competitions, as a rule, under the conditions of an intense rivalry. For example, during the performances of the national swimming team members in the World and Olympic Championships, starting with the 1990s, we can easily spot athletes who improved their results in these sports forums. To be more precise, only from 5 to $8 \%$ of the participants among the national team of Russia managed to improve their achievements in each of these competitions.

In essence, the entire training process of highly qualified athletes is aimed at achieving the best result in the most important competition. While in practice we observe failures to achieve planned results in the great majority of cases (see the example of the Russian national team - 92-95\%).

The failure to show a planned result in the competition is often explained by the loss of shape. At the same time, as a rule, it is not analysed properly which of the factors (physical, functional, psychological, etc.) uniting the concept of a physical shape has not contributed to the implementation of a planned result.

According to experts, the most common reason for the decrease in effectiveness during competitions, especially under conditions of highly intense sports competition, is the athlete's insufficient psychological readiness to improve or repeat the best previously achieved result [11]. In many sports, including sports swimming, in the pre-start period the absence of a scientifically justified formation of an athlete's internal state (as a winning athlete), which serves the successful implementation of physical conditions in competitive activities, largely determines numerous cases of effectiveness' decrease under the conditions of important competitions, i.e., a decrease in sports results compared to the best results available in the athlete's asset [3]. At the same time, the results of the survey involving trainers and pedagogical observations show that means and methods aimed at the great spirit development are extremely rarely used in the process of training.

Such statements can be proved by the results, showing that in tough competition between participants extreme conditions are created where their strong-willed fighting readiness of an athlete largely determines the success of his or her performance, including the achievement of his or her best result under these conditions [15].

Before the competition and in the process of it, due to the absence of an appropriate individual psychological and pedagogical training, an athlete often experiences excessive nervous tension, negatively affecting various areas of behavioural activity (emotional state, unconscious elements of behaviour, etc.), which eventually results in an effectiveness' decrease during the competitive activity [7].

Thus, one can regard the psychological and mobilisation abilities of an athlete as one of the attributes of a successful performance in competitions along with technical, physical and other characteristics of a competitive activity [1].

It is noted that by delivering regular and successful performances in competitions, an athlete can form a great pre-launch emotional state, which allows him or her to confidently and successfully perform in the future competitions [14]. However, practice shows that this algorithm is observed in exceptional cases only. Whereas due to the failure to deliver a successful performance, including not fulfilling a planned result in a competition, an unstable or alarming state often appears during the preparation for the competition and participation in it, tending to increase under the conditions of an acute sports rivalry. With unsuccessful repeated performances, the negative pre-launch psychological state of an athlete constantly increases [2]. In the expression [6],... "despite athlete's excellent physical, 
technical and functional fitness, lowered psychological stability or increased anxiety do not allow him or her to achieve the best result in a competition."

The goal of the research was to study the forming of a mobilisation state of highly qualified swimmers, enabling a sportsman to improve or repeat his or her best sports result during a competition.

The main task of the research was to improve or repeat the best result of a sportsman during a sports competition involving an intense rivalry through the relief of an excessive emotional strain (anxiety) and achievement of the highest possible level of mobilisation pre-start condition of a sportsman.

\section{Organization and methodology of the research}

22 swimmers ranging from the 1st sports category to the master of sports took part in the pedagogical experiment. Three weeks before the important competitions, psychological and pedagogical experiments, aimed at creating a mobilisation spirit among the athletes to improve their best achievements under the conditions of a severe competition, were carried out.

Psychological testing and interviewing were used to determine reduced accentuation zones, to understand and analyse internal state (reflection) and readiness for competition. The tests of Spielberger-Hanin and Eysenck [9] were used. The assessment of spirit, wellbeing and ratio of individual functional state indicators was carried out, using Sanitary Athletic Standards [10].

Psychological and pedagogical individual influences on swimmers-subjects were carried out, using environmental methods, psychotherapeutic and pedagogical techniques and taking into account individual results of preliminary tests and interviews [12]. An individual set of dominants was chosen with temporary and permanent encouragement. A great role in the development of a winning athlete's mobilisation abilities was assigned to the ability to independently correct one's psychological mood [8].

Psychological and pedagogical influences were carried out according to the scheme: psychotherapeutic inspiration $\rightarrow$ heterotraining $\rightarrow$ autotraining. At the same time, the compulsion turned into autotraining. As a result, psychological and pedagogical settings turned into ideomotoric training for the formation of mobilisation abilities, maintaining an equilibrium psychological state and dispelling increased anxiety.

During the development of strong-willed qualities, an internal composure, determination and other mobilisation characteristics, the attention of the athletes was focused on exceeding their best results under the conditions of an intense competition in all cases of psychological and pedagogical influences. [4].

\section{Results and discussion}

At the end of the pedagogical experiment, 18 highly qualified swimmers out of 22 athletes who took part in the experiment, i.e. about $82 \%$, improved or repeated their best results previously recorded in other starts under the conditions of the main competition of the season involving a highly intensive rivalry. After the heats, all swimmers who improved and repeated their best achievements (3 athletes) thought that a pre-launch internal composure, balance and confidence, along with a conceivable overcoming of the distance, helped them to achieve their new best result. In the process of overcoming the distance, they experienced ease while interacting with water and faith in their success. In Table 1, changes in the participants' results before and after the experiment are shown. 
Table 1. The results shown by participants during swimming pratice at a certain distance before and after the pedagogical experiment.

\begin{tabular}{|c|c|c|c|c|c|}
\hline $\mathbf{N o}$ & Sex & Distance & $\begin{array}{c}\text { The result before } \\
\text { the experiment } \\
\text { June 2019 }\end{array}$ & Claimed result & $\begin{array}{c}\text { Final result } \\
\text { June 2019 }\end{array}$ \\
\hline $\mathbf{1}$ & W & 50 backstroke & 30.85 & 30.80 & 30.77 \\
\hline $\mathbf{2}$ & W & 50 freestyle & 26.58 & 26.50 & 26.58 \\
\hline $\mathbf{3}$ & M & 100 butterfly & 58.99 & 58.80 & 58.62 \\
\hline $\mathbf{4}$ & M & 50 backstroke & 27.60 & 27.60 & 27.62 \\
\hline $\mathbf{5}$ & W & 100 breast & 1.09 .00 & 1.08 .90 & 1.08 .31 \\
\hline $\mathbf{6}$ & W & 100 butterfly & 1.05 .94 & 1.05 .60 & 1.05 .07 \\
\hline $\mathbf{7}$ & W & 50 breast & 31.75 & 31.75 & 31.75 \\
\hline $\mathbf{8}$ & M & 100 freestyle & 53.21 & 53.15 & 53.56 \\
\hline $\mathbf{9}$ & M & 100 breast & 1.06 .52 & 1.06 .35 & 1.06 .08 \\
\hline $\mathbf{1 0}$ & M & 50 breast & 30.13 & 30.10 & 30.10 \\
\hline $\mathbf{1 1}$ & M & 50 breast & 30.34 & 30.30 & 30.34 \\
\hline $\mathbf{1 2}$ & W & 100 butterfly & 1.04 .04 & 1.03 .90 & 1.03 .66 \\
\hline $\mathbf{1 3}$ & W & 50 backstroke & 30.41 & 30.40 & 30.36 \\
\hline $\mathbf{1 4}$ & W & 50 butterfly & 29.39 & 29.30 & 29.24 \\
\hline $\mathbf{1 5}$ & W & 100 freestyle & 55.86 & 55.73 & 55.70 \\
\hline $\mathbf{1 6}$ & W & 100 & 1.05 .12 & 1.05 .00 & 1.04 .91 \\
\hline $\mathbf{1 7}$ & W & 50 freestyle & 27.53 & 27.50 & 27.36 \\
\hline $\mathbf{1 8}$ & M & 100 breast & 1.02 .27 & 1.02 .20 & 1.02 .02 \\
\hline $\mathbf{1 9}$ & W & 100 freestyle & 1.00 .33 & 1.00 .00 & 1.00 .56 \\
\hline $\mathbf{2 0}$ & W & 100 breast & 1.16 .10 & 1.16 .00 & 1.15 .03 \\
\hline $\mathbf{2 1}$ & W & 50 breast & 34.92 & 33.90 & 33.98 \\
\hline $\mathbf{2 2}$ & M & 100 butterfly & 59.00 & 59.00 & 58.91 \\
\hline
\end{tabular}

Judging by these statements and the results shown by the participants of the experiment. it can be concluded that the use of the above-mentioned psychological and pedagogical methods positively affects their competitive activities.

At the same time. it should be noted that not all swimmers were able to improve their previous results. cope with anxiety and form properly a mobilisation fighting spirit when participating in competitive activities. It can be assumed that some swimmers (18\%) among the participants of the experiment. who showed relatively low results in a pre-start psychological testing. did not form the mobilisation qualities of a winning athlete at an adequate level. due to a reduced mental resistance. To some extent. this fact confirms the coaches' opinion about the presence of athletes with dominant features of extroverts tending to have an increased neuroticism and anxiety among high qualification swimmers.[5].

From the results of the poll among participants of the pedagogical experiment. using the Eysenck test. it can be concluded that during the competitions the level of anxiety was higher than before them. The reason for this can be that sportsmen experienced stress just before the start. The majority of sportsmen had even indicators of anxiety. However. 4 participants had much higher indicators. This fact suggests that the sportsmen lost their confidence due to increased anxiety and stress. An average level of aggressiveness was high during a pre-competition state. It appears that this is connected with a fighting character of a sportsman. During the pre-competition and competition stage. the level of rigidness remained almost the same for all experiment participants.

The results of the conducted surveys among the participants of the pedagogical experiment using the Spielberger-Hanin. Eysenck and SAN tests 3 weeks before the competition (pre-competition stage) and before the performance in the competition 
(competition period) are shown in Table 2. From the results of the surveys. it can be learnt that situational anxiety increases during a competition. Most likely. this happens due to the emotional stress of athletes before the competition. This condition of athletes can be different in intensity and time and occur as an emotional reaction to a stressful situation. It should be noted that individual swimmers had a high level of anxiety in the pre-competition period. During the competition period. the anxiety index increased for all survey participants. According to the results of personal anxiety. the indicators of the participants were in the same range for the pre-competition and competition stages. This fact may indicate that highly qualified swimmers are able to control their psychological state in different situations.

Table 2. The results of the poll among experiment participants. using Spilberger-Hanin. Eysenck and SAN tests during pre competition and competition stages.

\begin{tabular}{|c|c|c|c|c|c|c|c|}
\hline Tests & Stage & $\begin{array}{c}\text { Situation } \\
\text { al }\end{array}$ & $\begin{array}{c}\text { Self- } \\
\text { assessment }\end{array}$ & Anxiety & $\begin{array}{c}\text { Frustrati } \\
\text { on }\end{array}$ & $\begin{array}{c}\text { Aggressi } \\
\text { veness }\end{array}$ & Rigidness \\
\hline \multirow{2}{*}{$\begin{array}{l}\text { Spilberg } \\
\text { en- } \\
\text { Hanin. } \\
\text { Eysenck }\end{array}$} & $\begin{array}{l}\text { Pre- } \\
\text { compet } \\
\text { ition }\end{array}$ & $34.7 \pm 1.6$ & $38.9 \pm 1.2$ & $5.0 \pm 0.9$ & $7.1 \pm 1.1$ & $8.8 \pm 0.8$ & $7.2 \pm 0.9$ \\
\hline & $\begin{array}{l}\text { Compe } \\
\text { titon }\end{array}$ & $40.4 \pm 1.6$ & $39.0 \pm 1.0$ & $9.6 \pm 0.8$ & $7.4 \pm 1.1$ & $9.7 .1 \pm 0.9$ & $6.6 \pm 07$ \\
\hline \multirow{3}{*}{$\begin{array}{l}\text { SAN } \\
\text { poll } \\
\text { (general } \\
\text { state. } \\
\text { activity } \\
\text { level. } \\
\text { mood) }\end{array}$} & Stage & $\begin{array}{c}\text { General } \\
\text { state }\end{array}$ & $\begin{array}{c}\text { Activity } \\
\text { level }\end{array}$ & Mood & & & \\
\hline & $\begin{array}{l}\text { Pre- } \\
\text { compet } \\
\text { ition }\end{array}$ & $5.7 \pm 0.2$ & $4.9 \pm 0.3$ & $5.7 \pm 0.2$ & & & \\
\hline & $\begin{array}{l}\text { Compe } \\
\text { tition }\end{array}$ & $5.8 \pm 0.2$ & $5.5 \pm 0.1$ & $5.9 \pm 0.1$ & & & \\
\hline
\end{tabular}

Analyzing the obtained results. we can talk about mutual enrichment of the psychopedagogical set-ups implementation and autotraining. aimed at the dynamic equilibrium of homeostatic mechanisms. At the same time. it should be noted that in the process of mastering psychological and pedagogical set-ups and autotraining. there is an increase in the self-regulation of the body's own psychological resources. which. in turn. opens the way for further expansion and development of individual potential mobilisation abilities.

The acquisition of new skills and abilities to regulate its mobilization state. as our observations showed. allows an athlete to expand and develop independently his capabilities and implement actions suitable for him personally. The mentioned data. including the psychological state during competitive activity. confirms the effectiveness of the developed scheme involving psychological and pedagogical influences and the mechanisms of accreditation programs implementation.

\section{Conclusions}

1. Applying pre-start psychological and pedagogical influences aimed at the development of mobilization abilities characterizing a winning athlete state contributes to the achievement of an individual's best result; the improvement of performance in competitions under the conditions of a severe and important rivalry;

2. Possibility of pre-start internal composure. faith in improvement of the previous best achievement by swimmers of high qualification is achieved by using psychological and 
pedagogical individual influences. which include psychotherapeutic inspiration. heterotraining and autotraining.

\section{References}

1. A.A. Bobrishchev. Psychological personality features of athletes - representatives of martial arts with various levels of mental readiness// Scientific notes of the university named after P.F. Lesgaft. - No 1. - Pp. 10-14. (2009).

2. Conflict and Health. Springer Nature. Social Sciences: Health (social science). Medicine: Public Health. Environmental and Occupational Health. (2020).

3. Extreme Physiology and Medicine. Springer Nature. Medicine: Orthopedics and Sports Medicine. Biochemistry. Genetics and Molecular Biology: Physiology Medicine: Physiology (medical). (2018).

4. Frontiers in Physiology. Frontiers Media S.A. Medicine: Physiology (medical). Biochemistry. Genetics and Molecular Biology: Physiology. (2020).

5. G.A. Gilev. Problems in optimizing the process of training high-class athletes / G.A. Gilev. I.V. Ugolkova//Materials of the VII International National Congress "Modern Olympic Sport and Sports for All." - M.: Sports AkademPress. - T. 3.- Pp. 156-157. (2003).

6. V.N. Gladkov. Psychopressing leadership: on the issue of personality modification: experience in the comprehensive application of psychotherapeutic methods in the sport of higher achievements/V.N. Gladkov. - M.: Soviet Sport. - 187 pages. (2007).

7. G.D. Gorbunov. Psychopedagogics of sports: Educational manual. - M.: Soviet sport.312 pages. (2012).

8. E.I. Green. Mental burnout in sports: theoretical models and causes of the phenomenon // Man. Community. Management.- No. 4 (73). - Pp. 68 - 75. (2009).

9. A. A. Karelin. The Great Encyclopedia of psychological tests // M.: Eksmo.- 411 pages. (2007).

10. Personnel Psychology. Wiley-Blackwell. Business. Management and Accounting: Organizational Behavior and Human Resource Management. Psychology: Applied Psychology. (2020).

11. Physiological Reports. Wiley-Blackwell. Medicine: Physiology (medical). Biochemistry. Genetics and Molecular Biology: Physiology. (2020).

12. V.S. Vasilenko. Stress cardiomyopathy in highly qualified athletes (pathogenesis. early diagnosis): dissertation of the Medical sciences Master. St. Petersburg: Military Medical Academy. - 235 pages. (2012).

13. V.V. Vladykina. G.A. Gilev. V.N. Gladkov. Mobilization of the mental readiness of the athlete's performance in responsible competitions by the method of sovereign formation of a dominant with a pop-up installation//Pedagogy and psychology of education. -158 pages. (2018).

14. V.V. Vladykina. G.A. Gilev. V.N. Gladkov. Psychological training of an athlete//Scientific and theoretical journal "Scientific notes of the University named after P.F. Lesgaft." No. 1.- 294 pages. (2018).

15. V.V. Vladykina. G.A. Gilev. N.E. Maximov. A.A. Pleshakov. Development and teaching of sportsmanship with an orientation on model characteristics/Theory and practice of physical culture. No. 12 (966). - 32 pages. (2018). 